\title{
Faktor-Faktor yang Mempengaruhi Minat Menggunakan Layanan Mobile Banking di Batam
}

\author{
Ronny Lim \\ Universitas Internasional Batam \\ Ronnylim1306@gmail.com
}

\author{
Lady \\ Universitas Internasional Batam \\ lady@uib.ac.id
}

\begin{abstract}
Abstrak Kemajuan teknologi saat ini berperan besar dalam kemajuan perbankan digital yang memungkinkan penggunaan teknologi untuk melakukan transaksi perbankan dengan lebih mudah dan efisien. Mobile banking memiliki banyak manfaat bagi pihak bank dan nasabah. Keuntungan bank dalam banyak aspek memiliki keunggulan kompetitif atas bankbank yang tidak menyediakan layanan ini, menjangkau segmen tambahan pelanggan perorangan dan perusahaan yang memanfaatkan kemajuan dan inovasi telepon seluler dan mengurangi biaya karyawan, kurir, komunikasi, dokumen dan lainnya. Penelitian ini yang dilakukan untuk menyelidiki faktor-faktor yang berkaitan dengan minat nasabah bank nasional untuk menggunakan layanan mobile banking pada 200 nasabah dari bank nasional di Batam. Penelitian dimulai dengan mengumpulkan jawaban dari responden dengan kuesioner untuk kemudian diuji dengan menggunakan angka-angka statistika. Berdasarkan hasil uji dengan PLS diketahui bahwa hipotesis 2 dan 3 yaitu perceived ease of use dan perceived trust yang memiliki pengaruh dengan minat untuk menggunakan mobile banking namun 2 variabel indepnden lainnya yaitu perceived usefulness dan perceived risk tidak berpengaruh signifikan.
\end{abstract}

Kata Kunci perceived usefulness, perceived ease of use, perceived risk, perceived trust dan behavioral intention

\section{PENDAHULUAN}

Perbankan digital memungkinkan penggunaan teknologi untuk melakukan transaksi perbankan dengan lebih lancar dan efisien. Selain itu, persepsi publik tentang layanan perbankan digital yang benar-benar baru belum dieksplorasi dalam studi sebelumnya. Layanan yang ditawarkan oleh lembaga keuangan juga terus menantang dan memenuhi sikap konsumen yang menerima produk teknologi baru untuk mendapatkan peluang pasar. Ini akan menjadi lebih kompleks dari sebelumnya, dengan partisipasi pemain baru dari lembaga keuangan yang belum mapan seperti fintech. Menurut Al-Jabri (2015) teknologi ini menjanjikan penyederhanaan dan otomatisasi di masa depan. Teknologi dibidang jasa juga terus berkembang di berbagai pasar ritel.

Menggunakan berbagai platform, layanan dibuat untuk memungkinkan perangkat seluler melakukan banyak aktivitas internet tradisional, meskipun dalam format yang diperkecil untuk perangkat seluler. Ponsel telah memberikan kesempatan bagi lembaga 
perbankan untuk memperkenalkan layanan baru kepada masyarakat. Layanan terbaru, yang kini tersedia di lembaga perbankan di Indonesia adalah layanan mobile banking ( $\mathrm{m}$ banking). Ini adalah salah satu pendekatan terbaru untuk pembentukan layanan keuangan melalui teknologi komputer informasi, yang dimungkinkan oleh penggunaan ponsel secara luas bahkan di negara-negara berpenghasilan rendah (Nawaz dan Yamin 2018). Berdasarkan data yang diperoleh dari databooks, pengguna layanan mobile banking merupakan penyumbang terbesar transaksi pada salah satu bank swasta di dindonesia yaitu BCA pada tahun 2021 dengan persentase sebesar $61,55 \%$ dimana lebih dari setengah jumlah transaksi di BCA yaitu sebanyak 10,11 miliar kali transaksi yang dilakukan oleh nasabah dengan menggunakan layanan mobile banking.

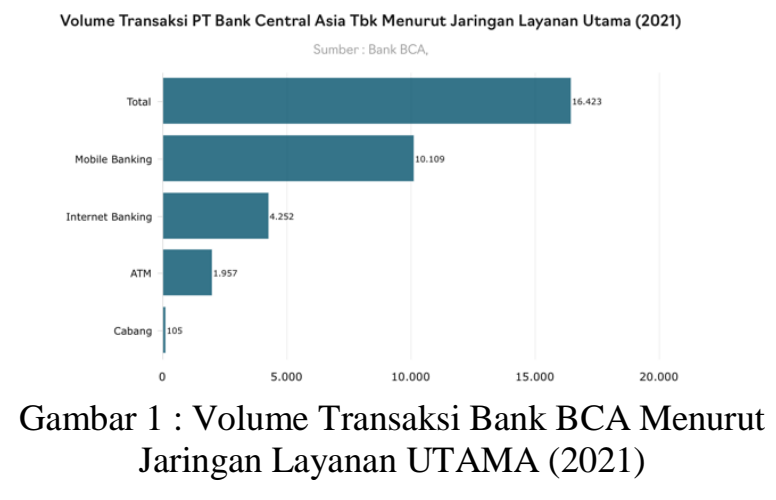

Menurut Rahi et al., (2017) M-banking memiliki manfaat bersama bagi bank dan nasabah; yang menguntungkan bank dalam banyak aspek, memiliki keunggulan kompetitif atas bank-bank yang tidak menyediakan layanan ini, menjangkau segmen tambahan pelanggan perorangan dan perusahaan yang memanfaatkan perluasan inovasi seluler, dan mengurangi biaya karyawan, kurir, komunikasi, dokumen dan lainnya (Kasim et al., 2017). Sedangkan dari sisi nasabah mobile banking merupakan sebuah aplikasi yang dapat diunduh di ponsel sehingga nasabah dapat melakukan transaksi bank dimanapun dan kapanpun dengan menggunakan perangkat genggam yang dapat dipindahkan. Bermanfaat bagi nasabah dalam banyak aspek, Bahkan mobile banking lebih bermanfaat daripada internet banking dalam hal tidak perlu login ke terminal komputer untuk menjaga transaksi perbankan (Chavali dan Kumar 2018).

\section{LANDASAN TEORI}

Penelitian Sharma (2018) memiliki tujuan untuk menyelidiki faktor yang berkaitan dengan minat nasabah dalam mengadopsi layanan mobile banking di India yaitu persepsi kemudahan, persepsi manfaat, kredibilitas perbankan, resiko dan sikap dari nasabah terhadap layanan mobile banking tersebut. Rahi et al., (2017), dalam penelitiannya mengobservasi mengenai minat nasabah bank di Pakistan terhadap layanan mobile banking yang semakin banyak digunakan oleh nasabah karena alasan praktis dan lebih cepat. Penelitian yang dilakukan Kasim et al. (2017) bertujuan untuk menganalisis tren layanan bank yang semakin popular yaitu mobile banking pada nasabah bank yang mengadopsi layanan mobile banking di Malaysia. Penelitian Al-Jabri (2015) memiliki tujuan untuk menunjukkan dalam penelitiannya menggunakan 253 nasabah perbankan di Arab Saudi sebagai responden penelitian. Jumlah nasabah yang mengadopsi layanan ini terus me ningkat setiap tahun menunjukkan kebutuhan nasabah yang semakin mobile dan membutuhkan layanan ini untuk transaksi perbankan yang lebih cepat. Berdasarkan penelitian Chiam et al. (2017) minat pelajar dalam menggunakan layanan digital dalam 


\section{JESYA}

JURNAL EKONOMI \& EKONOMI SYARIAH

Jurnal Ekonomi \& Ekonomi Syariah Vol 5 No 1, Januari 2022

E-ISSN : 2599-3410 | P-ISSN : 2614-3259

DOI : https://doi.org/10.36778/jesya.v5i1. 677

proses belajar mengajar di China. Dalam penelitian Bakar et al. (2017) responden penelitian yang merupakan nasabah bank di Malaysia. Penelitian Mostafa dan Eneizan (2018) bertujuan untuk mengetahui faktor-faktor yang berkaitan dengan pemakaian mobile banking di Libya. Penelitian Nawaz dan Yamin (2018) dalam persepsi kemudahan, persepsi manfaat pada nasabah yang menggunakan layanan digital banking di Srilanka. Dalam penelitian Muchingami (2018) menganalisis persepsi pelanggan tentang mobile banking di Botswana. Untuk memenuhi tujuan dari makalah, Lin dan Shiqian (2018) mengumpulkan data dari 500 responden pengguna e-banking di China. Penelitian Karma et al., (2014) ini bertujuan untuk mengidentifikasi faktor-faktor utama yang mempengaruhi adopsi layanan M-banking di Sudan. Penelitian Hassan (2014) menganggap lima faktor yang dirasakan kegunaan, norma subjektif, persepsi kemudahan penggunaan, persepsi kredibilitas, kesadaran konsumen tentang mobile banking. Penelitian Sarce, Malikah, \& Junaidi (2019) bertujuan untuk menganalisis faktor-faktor yang mempengaruhi niat menggunakan internet perbankan berdasarkan model penerimaan teknologi. Tujuan penelitian Chavali \& Kumar (2018) untuk meneliti faktorfaktor yang mempengaruhi minat nasabah yang menggunakan mobile banking. Penelitian Fadlan dan Dewantara (2018) bertujuan untuk menganalisis pengaruh variabel persepsi kemudahan terhadap penggunaan mobile banking. Penelitian Primanda et al. (2020) bertujuan untuk menganalisis dan membuktikan pengaruh persepsi kemudahan penggunaan, persepsi daya guna, persepsi kepercayaan dan persepsi manfaat berpengaruh terhadap minat nasabah untuk menggunakan e-money. Ngah et al. (2021) membuktikan bahwa faktor-faktor yang mempengaruhi perilaku pembelian online melalui persepsi kemudahan penggunaan, manfaat yang dirasakan, dan kepercayaan. Penelitian Arumi dan Yanto (2019) untuk mengetahui apakah ada pengaruh perceived of technology, perceived of risk, perceived of usefulness, subjective norm, perceived ease of use terhadap intention to use electronic banking. Studi penelitian Maduku (2014) menyelidiki mengenai niat perilaku klien perbankan ritel terhadap layanan mobile banking penggunaan di Afrika Selatan. Penelitian Hosseini et al., (2015) untuk mendeteksi faktor-faktor yang berpengaruh dalam menggunakan layanan mobile banking di Iran; Effendy, Hurriyati, dan Hendrayati (2021) menggabungkan keduanya model teoritis dan bertujuan untuk menentukan pengaruh kegunaan yang dirasakan, kemudahan yang dirasakan dari penggunaan, dan pengaruh sosial terhadap niat menggunakan $e$-wallet. Makalah singkat Lafraxo et al., (2018) menunjukkan model menguji perceived risk, security" dan trust". Penelitian Namira dan Susanto (2021) bertujuan untuk mengetahui pengaruh persepsi manfaat, efek kemudahan penggunaan e-money di Padang. Penelitian Singh dan Srivastava (2018) untuk mengetahui faktor-faktor yang mempengaruhi adopsi mobile banking di India. Isma et al., (2021) membuktikan kemudahan penggunaan dan efek persepsi risiko pada niat perilaku untuk menggunakan e-money di Padang. Penelitian Abbas et al., (2018) difokuskan pada faktor pengaruh sosial, layanan keuangan, kepercayaan yang dirasakan, keuntungan relatif, risiko yang dirasakan.Studi Rehman dan Shaikh (2020) bertujuan untuk menguji faktor-faktor yang mempengaruhi niat perilaku nasabah terhadap mobile banking di Malaysia. Penelitian Tiong (2020) bertujuan untuk menyelidiki hubungan konstruk inti seperti kompatibilitas, kegunaan dan kemudahan penggunaan konsumen.

Pengaruh Perceived Usefulness terhadap Behavioral Intention 
Menurut Kasim et al., (2013), Perceived Usefulness sangat memprediksi adopsi m-banking di Singapura. Sebuah penelitian yang dilakukan pada adopsi m-banking di Malaysia menambahkan atribut baru seperti risiko yang dirasakan, kredibilitas yang dirasakan dan kesadaran pelanggan untuk mempergunakannya dan menemukan bahwa Perceived Usefulness sangat mempengaruhi, diikuti oleh kredibilitas dan kesadaran, adopsi m- perbankan di Malaysia.

\section{Pengaruh Perceived Ease of Use terhadap Behavioral Intention}

Menurut Kasim et al., (2013), model penerimaan teknologi memerlukan keyakinan pengguna untuk memutuskan cara atau pendekatan yang akan diambil terkait dengan sistem yang diterapkan. Sebagai imbalannya, keyakinan ini dapat membantu pengembangan tujuan bagi konsumen untuk menggunakan layanan atau produk.

\section{Pengaruh Perceived Trust terhadap Behavioral Intention}

Perceived Trust adalah kemungkinan yang diharapkan bahwa pelanggan percaya bahwa tindakan kelompok yang dipilih akan dilakukan dengan cara yang tepat sesuai dengan harapan mereka yang pasti. Aktivitas perdagangan elektronik diterima setelah ditunda selama jangka waktu tertentu karena kurangnya kepercayaan. Kepercayaan memainkan peran penting pada ide-ide dan pandangan konsumen tentang m-banking. Penelitian sebelumnya dari Chiam et al. (2017), Mostafa dan Eneizan (2018), Nawaz dan Yamin (2018), Karma et al., (2014), Hassan, (2014), Sarce et al., (2014) Laily (2018), Maduku (2014), Lafraxo et al., (2018), Namira et al., (2021), Abbas et al., (2018), Rehman dan Shaikh (2020) menunjukkan hubungan yang signifikan positif dari variabel perceived trust terhadap behavioral intention.

\section{Pengaruh Perceived Risk terhadap Behavioral Intention}

Melakukan transaksi elektronik merupakan risiko yang dihadapi konsumen karena tidak adanya kontak fisik yang selanjutnya; mempengaruhi adopsi teknologi internet, (Cheng \& Tsai 2011). Dalam studi ini Risiko dikaitkan dengan kemungkinan kerugian dari transaksi m-banking karena menyangkut lingkungan virtual tanpa interaksi dengan karyawan, bukan lingkungan tradisional. Pudaruth \& Ramdin (2012) menganggap risiko yang dianggap sebagai salah satu penentu pembelian online dan mereka menemukan bahwa hal itu sangat mempengaruhi pembelian.

Berikut adalah perumusan model dan hipotesis penelitian;

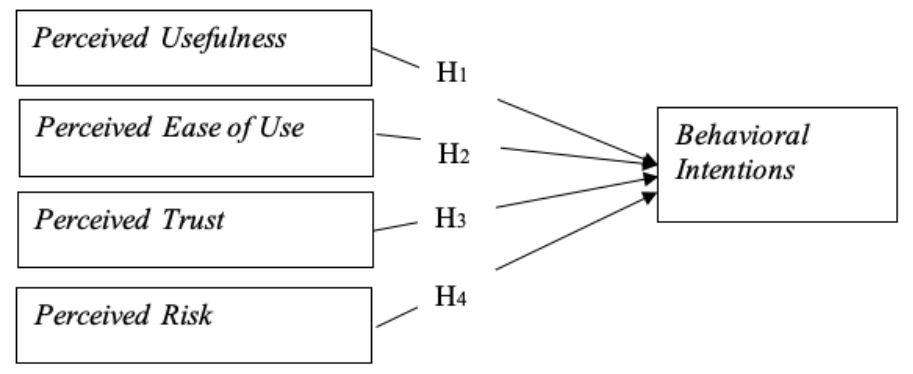

Berdasarkan kerangka model di atas maka hipotesis dirumuskan sebagai berikut:

H1: Terdapat pengaruh signifikan positif antara perceived usefulness terhadap behavioral intention

H2: Terdapat pengaruh signifikan positif antara perceived ease of use terhadap behavioral intention

H3: Terdapat pengaruh signifikan positif antara perceived trust terhadap behavioral intention 
H4: Terdapat pengaruh signifikan negatif antara perceived risk terhadap behavioral intention

\section{HASIL PENELITIAN}

\section{Hasil Evaluasi Model}

\section{Uji Outer Loadings}

Pengujian validitas umtuk mendapatkan jawaban kuesioner yang terindikasi secara tepat. Nilai outer loading dinyatakan valid apabila hasil signifikannya lebih besar dari 0,5 (Latan dan Ghozali, 2012). Berdasarkan tabel dibawah memberikan bukti pengujian uji validitas Average Variance Extracted. Hasil menyatakan bahwa valid karena semua nilai lebih besar dari 0,5 (Latan dan Ghozali, 2012). Uji Cronbach alpha ini bertujuan untuk menguji apakah datanya realibel, yang dinyatakan reliabel bila nilai cronbach alpha lebih besar dari 0,5 (Ghozali dan Latan 2012).

\section{Uji Inner Model}

\section{Path Coefficients (Direct Effects)}

Pengujian ini memberikan bukti bahwa terdapat pengaruh langsung dengan adanya variabel mediasi diantara hubungan variabel yang dikaji. Hasil uji menunjukkan hubungan yang signifikan bila nilai t-statistic melebihi 1,96 dan $\mathrm{P}$ values lebih kecil dari 0,05 .

\begin{tabular}{|c|c|c|c|}
\hline Variabel $(\mathrm{X} \rightarrow \mathrm{Y})$ & T-Statistics & P Values & Kesimpulan \\
\hline $\begin{array}{l}\text { Perceived Usefulness -> Behavioral } \\
\text { Intention }\end{array}$ & 0,963 & 0,336 & H1 Tidak Signifikan \\
\hline $\begin{array}{l}\text { Perceived Ease of Use -> Behavioral } \\
\text { Intention } \\
\text { Perceived Trust }>\text { Behavioral }\end{array}$ & 4,016 & 0,000 & H2 Signifikan \\
\hline $\begin{array}{l}\text { Perceived Trust -> Behavioral } \\
\text { Intention } \\
\text { Perceived Risk -> Behavioral }\end{array}$ & 2,784 & 0,005 & H3 Signifikan \\
\hline Intention & 1,757 & 0,079 & H4 Tidak Signifikan \\
\hline
\end{tabular}

Sumber : Data primer diolah (2021).

H1: Tidak terdapat pengaruh signifikan antara perceived usefulness terhadap behavioral intention. Berdasarkan hasil uji yang menunjukkan nilai T-statistic sebesar 0,963 yang berarti di bawah 1,96 sehingga disimpulkan tidak terdapat pengaruh signifikan dari perceived usefulness terhadap behavioral intention. Hasil penelitin ini tidak sesuai dengan peelitian dari Sharma (2018) Rahi et al., (2017), Kasim et al., (2017), Al-Jabri (2015), Chiam et al., (2017), Nawaz dan Yamin (2018), Mostafa and Eneizan (2018), Chavali dan Kumar (2018), Muchingami (2018).

H2: Terdapat pengaruh signifikan positif antara perceived ease of use terhadap behavioral intention. Berdasarkan hasil uji yang menunjukkan nilai T-statistic sebesar 4,016 yang berarti melebihi 1,96 sehingga dapat disimpulkan terdapat pengaruh signifikan dari perceived ease of use terhadap behavioral intention. Hasil uji ini sesuai dengan penelitian dari Sharma (2018) Rahi et al., (2017), Kasim et al., (2017), Al-Jabri (2015), Chiam et al. (2017), Nawaz dan Yamin (2018), Mostafa and Eneizan (2018), Chavali dan Kumar (2018). Muchingami (2018).

H3: Terdapat pengaruh signifikan positif antara perceived trust terhadap behavioral intention. Berdasarkan hasil uji yang menunjukkan nilai T-statistic sebesar 2,784 yang berarti melebihi 1,96 sehingga dapat disimpulkan bahwa terdapat pengaruh signifikan dari perceived trust terhadap behavioral intention. Hasil uji ini sesuai dengan penelitian 
dari Nawaz dan Yamin (2018), Rahi et al., (2017), Kasim et al., (2017), Chiam et al. (2017).

H4: Tidak terdapat pengaruh signifikan antara perceived risk terhadap behavioral intention. Berdasarkan hasil uji yang menunjukkan nilai T-statistic sebesar 1,757 yang berarti melebihi 1,96 sehingga dapat disimpulkan bahwa tidak terdapat pengaruh signifikan dari perceived risk terhadap behavioral intention. Hasil penelitian ini tidak sesuai dengan penelitian dari Al-Jabri (2015), Chavali dan Kumar (2018), Nawaz dan Yamin (2018), Mostafa and Eneizan (2018).

\section{KESIMPULAN}

Dari hubungan antar variabel yang telah diuji, maka kita dapat mengetahui akan faktor-faktor yang mempengaruhi behavioral intention pada layanan mobile banking di Kota Batam. Sehingga pihak bank yang menyediakan layanan mobile banking diharapkan dapat melakukan hal yang berupaya untuk menjaga dan meningkatkan kualitas layanan pada mobile banking yang dapat meningkatkan persepsi kegunaan, persepsi kemudahan penggunaan, persepsi kepercayaan serta persepsi resiko nasabah terhadap layanan mobile banking agar dapat meningkatkan niat konsumen dalam mengadopsi layanan perbankan digital. Hasil penelitian ini juga diharapkan dapat dijadikan sebagai referensi serta menajadi bahan pertimbangan untuk memperdalam penelitian selanjutnya dengan menggunakan variabel lainnya yang memepengaruhi minat nasabah untuk mengadopsi layanan mobile banking seperti perceived compatibility, subjective norms, social influence, dll.

\section{DAFTAR PUSTAKA}

Abbas, S.K, Hassan, H.A., Asif, J., Junaid, H.M and Zainab, F. 2018. "What Are the Key Determinants of Mobile Banking Adoption in Pakistan?" International Journal of Scientific \& Engineering Research 9 (2): $841-48$. https://doi.org/10.14299/ijser.2018.02.012.

Al-Jabri, I. M. 2015. "The Intention to Use Mobile Banking: Further Evidence from Saudi Arabia." South African Journal of Business Management 46 (1): 23-34. https://doi.org/10.4102/sajbm.v46i1.80.

Arumi, A, and Yanto, H. 2019. "Anteseden Penggunaan Layanan Electronic Banking Di Kalangan Mahasiswa ( Sebuah Kajian Technology Acceptance Model ).” Economic Education Analysis Journal 8 (1): 130-47.

Bakar, R.A, Najdah A.A, Muhammud, A and Muda, M . 2017. "Perceived Ease of Use, Security and Privacy of Mobile Banking." International Journal of Business and Social Research 2 (1): 56-62.

Chavali, K, and Kumar, A. 2018. "Adoption of Mobile Banking and Perceived Risk in GCC.” Banks and Bank Systems $13 \quad$ (1): 72-79. https://doi.org/10.21511/bbs.13(1).2018.07.

Chiam, C.C, Woo, T.K., Chung, H.T., and Kumar, R.N. 2017. "The Behavioural Intention to Use Video Lecture in an ODL Institution." Asian Association of Open Universities Journal 12 (2): 206-17. https://doi.org/10.1108/aaouj-09-2017-0030.

Effendy, F., Hurriyati, R and Hendrayati, H. 2021. "Perceived Usefulness, Perceived Ease of Use, and Social Influence: Intention to Use e-Wallet." Proceedings of the 5th Global Conference on Business, Management and Entrepreneurship (GCBME 2020) 187 (Gcbme 2020): 311-15. https://doi.org/10.2991/aebmr.k.210831.060. 
Fadlan, A, and Dewantara, R.Y. 2018. "Pengaruh Persepsi Kemudahan Dan Persepsi Kegunaan Terhadap Penggunaan Mobile Banking (Studi Pada Mahasiswa Pengguna Mobile Banking Universitas Brawijaya)." Jurnal Administrasi Bisnis (JAB) 62 (1): 82-89.

http://administrasibisnis.studentjournal.ub.ac.id/index.php/jab/article/viewFile/2652/ 3045.

Hassan, M.M., Rahman, A., Afrin, S and Rabbany, G. 2014. "Factors Influencing the Adoption of Mobile Banking Services in Bangladesh: An Empirical Analysis." International Research Journal of Marketing 2 (1): 9. https://doi.org/10.12966/irjm.02.02.2014.

Isma, R.A, Hudayah, S and Indriastuti, H. 2021. "The Influence of Perceived Usefulness, Perceived Ease of Use, and Perceived Risk on Purchase Interestand Use Behavior Through Bukalapak Application in Samarinda." Business and Accounting Research (IJEBAR) Peer Reviewed-International Journal 5 (3): 1247-58. https://jurnal.stieaas.ac.id/index.php/IJEBAR.

Karma, N.G, Siddig, B.I, and Ali, A.H. 2014. "Key Factors Affecting Mobile Banking Adoption Among Banks ' Customers in Sudan." International Journal of Liberal Arts and Social Science 2 (6): 112-22.

Kasim, A, Syahidah A, dan Mahathir, R. 2017. "A Study of Behavioral Intention to Use Mobile Banking in Malaysia." International Journal of Advanced Studies in Social Science \& Innovation (IJASSI) 1 (1): 1-17.

Lafraxo, Y, Fadoua, H, Hamza, A, and Amine, R. 2018. "The Effect of Trust, Perceived Risk and Security on the Adoption of Mobile Banking in Morocco." ICEIS 2018 Proceedings of the 20th International Conference on Enterprise Information Systems 2 (Iceis): 497-502. https://doi.org/10.5220/0006675604970502.

Ghozali, L. 2015. Partial Least Square Konsep Teknik Dan Aplikasi Menggunakan Program SmartPLS 3.0. 2nd ed. Semarang: Badan Penerbit Universitas Diponegoro.

Lin, L \& Shiqian, W. 2018. "Factors Influencing the Behavior Intention of E-Banking Transactions Through Mobile Phones in China." Journal of Internet Banking and Commerce 23 (1): 1-11. http://www.icommercecentral.com.

Maduku, D.K. 2014. "Behavioral Intention towards Mobile Banking Usage by South African Retail Banking Clients." Investment Management and Financial Innovations 11 (3): 58-72.

Mostafa, A.A.N., dan Eneizan, B. 2018. "Factors Affecting Acceptance of Mobile Banking in Developing Countries." International Journal of Academic Research in Business and Social Sciences 8 (1): 340-51. https://doi.org/10.6007/ijarbss/v8-i1/3812.

Muchingami, L. 2018. "An Analysis of Customer Perception on Mobile Banking in Botswana." International Journal of Innovative Research in Science, Engineering and Technology 7 (5): 5801-5. https://doi.org/10.15680/IJIRSET.2018.0705151.

Namira, N.V dan Susanto, P. 2021. "The Effect of Perceived Usefulness, Perceived Pase of Use, and Perceived Risk on Behavioral Intention to Use E-Money." Operation Maangement and Information System Atudies 1 (3): 133-44. https://doi.org/10.24036/omiss.v1i3.34. 